7

\title{
CHARACTERIZATION OF “OIL ON COPPER” PAINTINGS BY ENERGY DISPERSIVE X- RAY FLUORESCENCE SPECTROMETRY
}

\author{
A. Pitarch ${ }^{1}$, A. Ramón ${ }^{2}$, A. Álvarez-Pérez ${ }^{3}$, I. Queralt ${ }^{1}$ \\ ${ }^{1}$ Laboratory of X-ray Analytical Applications, Institute of Earth Sciences “Jaume Almera”, CSIC, Solé \\ Sabarís Street, 08028 Barcelona, Spain. \\ ²1926’ AR Art Gallery, Palla Street 25, 08002 Barcelona, Spain. \\ ${ }^{3}$ Department of Geology, Faculty of Sciences, Autonomous University of Barcelona, 08193 Bellaterra, \\ Barceloma, Spain.
}

\begin{abstract}
Energy dispersive X-ray fluorescence is a common analytical tool for layer thickness measurements in quality control processes in coating industry, but there are scarce microanalytical applications in order to ascertain semi-quantitative or quantitative information of painted layers. "Oil on copper" painting becomes a suitable material to be analysed by means of X-ray fluorescence spectrometry, due to the metallic nature of substrate and the possibility to apply layered models as used in coating industry. The aim of this work is to study the suitability of a quantitative EDXRF methodology for the assessment of the areal distribution of pigments and the characterization of painting methods on such kind of pictorial artworks. The method was tested on standard reference materials: dried droplets of monoelemental standard solutions laid on a metallic plate of copper. As an example of application, we estimated pigment mass distribution of two "oil on copper" painting from the sixteenth and eighteenth century respectively. Pictorial layers have been complementarily analyzed by X-ray diffraction.

Apart of the supporting media made of copper or brass, we could identify two different superimposed layers: a) a preparation layer mainly composed by white lead and b) the pictorial layer of variable composition depending on the pigments used by the artist on small areas of the painting surface. The areal mass distribution of the different elements identified in the painting pigments $(\mathrm{Ca}, \mathrm{Cr}, \mathrm{Mn}, \mathrm{Fe}, \mathrm{Zn}, \mathrm{Cd}$, $\mathrm{Hg}$ and $\mathrm{Pb}$ ) have been determined by elemental mapping of some parts of the artworks.
\end{abstract}

Keywords: non destructive analysis; EDXRF; pigment mass distribution; "oil on copper". 


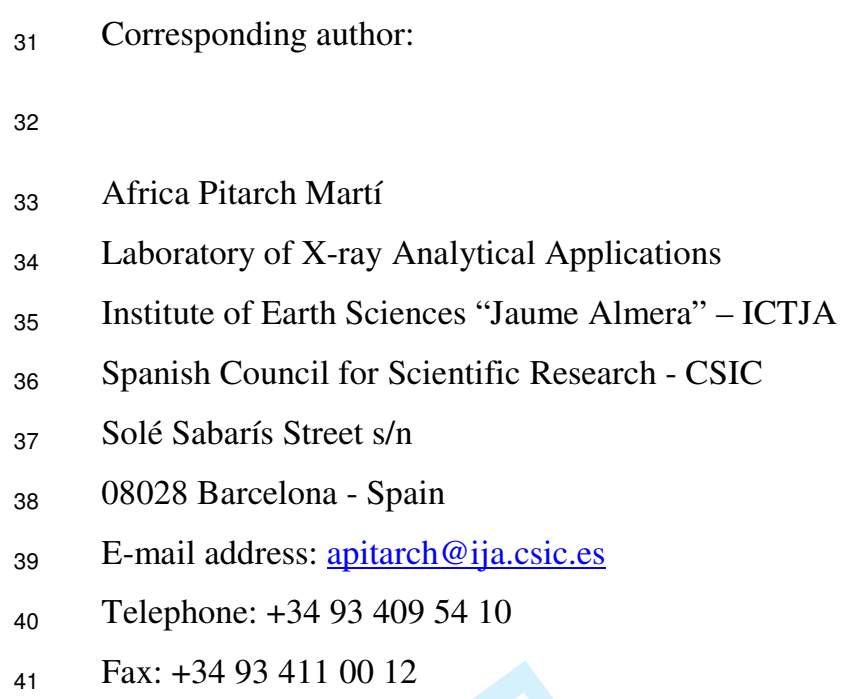




\section{Introduction}

The practice of painting in oil on a copper support has its origins in the sixteenth century in Italy and was widespread in the rest of Europe during the seventeenth century. The artists painted portraitures, landscapes and religious subjects on small sheets of copper or brass (often old printmaking plates) to decorate objects such as furniture or dresses. The painting technique had diverse stages; once the artist had obtained his copper plate, it required roughening prior to painting. Then, a priming coat (typically a thin layer of white lead and umber in oil) was laid down to also help the paint adhere [1]. This practice remained till the end of the nineteenth century, when lead grounds began to be substituted by zinc white grounds [2].

It is well known that Energy Dispersive X-ray fluorescence (EDXRF) is a common analytical tool for layer thickness measurements in many classical industrial applications, such as quality control processes in coating industry [3]. In the area of Cultural Heritage analyses EDXRF has become a powerful tool towards the obtaining of qualitative information about the chemical composition of inorganic pigments [4-8]. Moreover, recent studies reported that EDXRF spectrometry in combination with other techniques such as visible reflectance spectrometry (vis-RS) or even alone can be successfully applied, in a wide range of cases, to reconstruct stratigraphy and thickness of paint layers or even in photograph films [915]. In the particular area of quantitative analysis of multilayered paintings, there had been published some works [16-17], but there are no specific investigations in order to obtain semi-quantitative information of the areal distribution of pigments in a complete non-destructive way. In this way, this kind of artwork becomes a perfect material to be analysed by means X-ray fluorescence spectrometry, due to the metallic nature of the substrate. The aim of this work is to study the suitability of a quantitative EDXRF method designed specifically for the approximation of pigment mass distribution on "oil on copper" multilayer paintings.

\section{Materials and methods}

\subsection{Artworks}

Two "oil on copper" paintings from presumable different ages were selected for this study. Both of them belong to the private collection of 1926' AR Art Gallery (Barcelona, Spain). The first one represents a scene of a Franciscan habit Saint holding a wooden cross in his outstretched arms. The accuracy of the 
stroke and the employed colours (its palette is composed by green, golden, red, skin-coloured and brown in different tonalities) suggest that this is an Italian work made in the second half of the sixteenth century (Fig. 1). The second painting under study represents a river landscape scene. Although the painting it is in bad state of conservation (it has micro cracks in excess, probably due to the poor preparation of the copper plate) the colours are still very vivid (its palette is composed by white, yellow, pink, orange, deep red, brown, green and blue). Such kind of detailed scenes were in vogue during the eighteenth century, especially in the bourgeois Dutch market (Fig. 2).

The major requirement for this analytical study was the ability to perform non-destructive measurements, due to the historical value of both artworks. In a first stage, then, the "oil on copper" paintings were examined using non-destructive EDXRF to qualitatively determine the elemental composition of pigments present in the paintings. In addition, X-ray Diffraction (XRD) was also employed not only to reach information on the compositional properties of the painting by crystalline phase analysis but also to characterize the nature of the different layers for the proper development of the EDXRF layer model.

\subsection{XRD instrumentation}

The diffractometer used for the study of the artworks was a D8 Advance (Bruker AXS GmbH, Germany) instrument with a $\mathrm{Cu} \mathrm{K} \alpha$ target tube X-ray source (operating at $40 \mathrm{kV}$ and $40 \mathrm{~mA}$ ), a primary Göbbel mirror and an energy dispersive SOL-X detector. The samples were mounted on a mobile plate stage to adequately align the system, so that measurements were carried out in a completely non-destructive way, without previously preparing or adapting the sample for the analyses on the conventional sample holders.

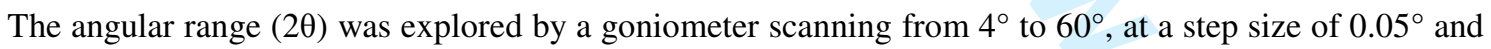
a counting time of 3 seconds per step. Evaluation of X-ray diffractograms was performed by using the routines of the Diffrac.Suite ${ }^{\mathrm{TM}}$ software package (Bruker AXS GmbH, Germany) and the attached specific powder diffraction file (PDF) database (International Centre for Diffraction Data - ICDD, Pennsylvania, USA).

\subsection{EDXRF equipment}

We used a bench top small-spot energy dispersive X-ray fluorescence spectrometer (XDV-SD® model, Helmut Fischer GmbH, Germany) designed for coating -thickness measurement and materials testing. It 
consists on a microfocus tungsten anode X-ray tube (using a maximum power of $50 \mathrm{~W}$, a maximum voltage of $50 \mathrm{kV}$ and a maximum current of $1 \mathrm{~mA}$ ) and a Si-Pin semiconductor detector (Peltier cooling at $-50^{\circ} \mathrm{C}$; with $180 \mathrm{eV} \mathrm{FWHM}$ at $\mathrm{Mn} \mathrm{K} \alpha$ ). The spectrometer is equipped with 5 primary filters (nickel $10 \mu \mathrm{m}$, molybdenum $70 \mu \mathrm{m}$, aluminium $500 \mu \mathrm{m}$ and $1000 \mu \mathrm{m}$ and titanium $300 \mu \mathrm{m}$ ) and four collimators $(0.1,0.3,1$ and $3 \mathrm{~mm}$ in diameter). A video camera allows viewing and selection of the irradiated area with up to $\times 45$ magnification and the motorized $X-Y-Z$ stage allows focusing and searching of the points of interest. The instrument can be used to obtain elemental chemical mappings by programming a grid of points for analysis.

\subsection{Standards for EDXRF calibration}

After the screening phase analysis carried out on the artworks, nine elements were selected for the preparation of a standard set used to calibrate the EDXRF instrument for the analysis of "oil on copper" paintings. Elemental stock solutions (TraceCERT®, Fluka, Sigma Aldrich Chemie, GmbH, Germany; $1000 \mathrm{mg} / \mathrm{L}$ ) of calcium, chromium, manganese, iron, zinc, cadmium, gold, mercury and lead were used for this purpose, following similar procedures than those reported by Fittschen and Havrilla [18] but at different scale. An aliquot of $1 \mu \mathrm{L}$ of each solution was transferred onto a copper support by using a micro-syringe (7000 Series Modified Microliter ${ }^{\mathrm{TM}}$, Hamilton, USA) and left to dry at room temperature before EDXRF analysis. We obtained some small dried residues, each one containing 1 microgram of the different considered elements. These dried residues have an approximate diameter around 600 microns.

\subsection{EDXRF quantitative method}

A methodology for analysis of "oil on copper" multilayered paintings was developed by using the WinFTM® Software Program version 6.20 (Helmut Fischer GmbH + Co. KG, Germany). This software program uses the fundamentals described in [19-20] for the evaluation of the measured spectrum and allows designing different layered models (single, double, multilayers) taking into account the main features of the layers and substrates. Amongst the possibilities and variables needed to define a method for the measuring layer, the program allows introducing the following spectral data: a) spectra of material's base of standards (a copper support in this case); b) spectra of the standards used for the calibration (monoelemental solutions) and c) spectra of the material's base of the samples to be analysed. This last point was fulfilled by the analysis of the backside of the "oil and copper" paintings. 
Looking for the best conditions for analysis of the previously prepared standard set, different conditions (filter, collimator, voltage and current) were checked. We used an aluminium filter of $1000 \mu \mathrm{m}$ in thickness (in order to reduce the background noise from tungsten tube at the region of interest in the spectrum) and the collimator of $1 \mathrm{~mm}$ in diameter (in order to adjust the X-ray focal spot for the irradiation of the whole dried droplet surface of calibration dataset). The spectra acquisition time was optimised to ensure that counting statistics is good enough to guarantee the quality of analytical results. We choose $50 \mathrm{kV}$ and $1000 \mu \mathrm{A}$ as voltage excitation and anode current respectively, taking into consideration the counting rates. To obtain the minor relative standard deviation (RSD), repeated measurements were carried out (on the same point and using the same analytical conditions, 6 analyses at different measuring times: 50, 100, 300, 500, $1000 \mathrm{~s}$ ). A measuring time of $300 \mathrm{~s}$ delivers an approximately RSD of $1 \%$ whilst a more extended time does not imply a significant reduction in the RSD value (Fig. 3). Then we select this counting time as the best for spectra obtaining at our instrumental design.

The detection limit $(D L)$ obtained by EDXRF were calculated according to the equation:

$$
D L=3 \frac{C_{i} \sqrt{N_{b}}}{N_{P}}
$$

where: $C_{i}$ is the concentration of the element $i ; N_{b}$ is the net peak area of the background and $N_{p}$ is the net peak area of the analytical line of the element $i$. The results for the standard set are presented in Table 1 .

Once the methodology for routine analysis of "oil on copper" multilayered paintings was tuned up, and taking into consideration the particular features of both artworks, measurements were carried out by using a voltage excitation of $50 \mathrm{kV}$, an anode current of $1000 \mu \mathrm{A}$, an aluminium filter of $1000 \mu \mathrm{m}$ in thickness, a spectrum measuring time of $300 \mathrm{~s}$ and a focal spot of $1 \mathrm{~mm}$ in diameter. Chemical mappings were also carried out in order to observe the distribution of elements along selected areas of the paintings. Measuring conditions were the same ones as the defined for punctual analyses with exception of the counting time, which was reduced to $60 \mathrm{~s}$ per each point due to the large number of measurements to be done. In some cases we analysed some artwork details smaller than $1 \mathrm{~mm}$ by using the $0.3 \mathrm{~mm}$ collimator mask then determining the elemental concentration by the areal ratio of both focal spots ( 1 and $0.3 \mathrm{~mm})$. 


\subsection{Statistical data treatment}

Once we quantified the elements from both artworks, we tried to identify clustering concerning the different colouration by using Principal Component Analysis (PCA). The main objective of PCA is to simplify the study of complex data systems by identifying a relative small number of components that can be used to represent relationships amongst groups of many interrelated discrete variables, in this case the features of both studied artworks. Statistical analysis was performed with the software package STATISTICA 7.0.

\section{Results and discussion}

3.1. Elemental and crystalline phase analyses of the supporting materials and preparation layers.

Analysis of the supporting material was made by obtaining an EDXRF spectrum from the backside of each plate, in which we only can distinguish the signal from copper and minor titanium, iron and lead impurities at trace level, thus deducing the use of pure copper plate as a supporting material of the Franciscan Saint painting (Fig. 4a). The river landscape painting exhibit copper and zinc as a major elements, joined by titanium, iron and lead impurities at trace level, thus deducing the use of zinc-bearing brass plate as a supporting material (Fig. 4b). XRD spectral data of the painting side supported these results, revealing the presence of the characteristic peaks a copper based alloy (Fig. 5a, see peaks labelled as \#) and brass (Fig. 5b, see peaks labelled as $\beta$ ).

The omnipresence of lead all over the painting showed an important role of some lead compound, so that it was investigated by X-ray diffraction. As it was previously mentioned, the painting technique on such kind of supports was usually based on laying down one white lead thin layer to promote enough roughness to help oil paint adhere [1]. XRD experimental data confirmed the presence of hydrocerussite (Fig. 5a, see peaks labelled as *) which is a lead carbonate hydroxide mineral with the composition $\left(\mathrm{Pb}\left(\mathrm{CO}_{3}\right)_{2} \cdot \mathrm{Pb}(\mathrm{OH})_{2}\right)$ and cerussite $\left(\mathrm{PbCO}_{3}\right)$ (Fig. 5b, see peaks labelled as \&). These terms should properly refer to the natural mineral forms, so further on we will refer to the pigment as lead white. Although the artificial form was synthesised since ancient times, the fact that we only identified lead white in the preparation layer would confirm that both artworks were surely done before the nineteenth century. 


\subsection{Pigment mass distribution estimation on a Renaissance painting}

As revealed by the spectral data obtained by EDXRF analyses we can distinguish the presence of calcium, manganese, iron, copper, gold, mercury and lead.

Copper signal is present in all the spectra and it can appear as a result of the emission of copper from support and by its potential presence in the pigments of green colouration. However, as we cannot clearly differentiate by EDXRF experimental data the origin of the copper signal in the spectra, the estimated areal concentration cannot be distinguished. Nevertheless, the contribution from the support is clearly ascertained from the attenuation of $\mathrm{Cu} \mathrm{K} \alpha$ line intensity in the carnations, due to the strong lead-bearing pigment absorption. Despite the fact that the contribution of copper based pigments cannot be distinguished by EDXRF analysis, XRD experimental data (Fig. 5a) confirmed the presence of basic copper sulphates such as brochantite $\left(\mathrm{Cu}_{4}\left(\mathrm{SO}_{4}\right)(\mathrm{OH})_{6}\right)$ and posnjakite $\left(\mathrm{Cu}_{4}\left(\mathrm{SO}_{4}\right)(\mathrm{OH})_{6} \cdot \mathrm{H}_{2} \mathrm{O}\right)$. The first mention of the use of these pigments dates back to the seventeenth century [21].

The main results relating to the elemental chemistry of the Renaissance painting are summarized in Table 2. The relationship between colouration and chemical data can be deduced from the elemental surface distribution reported in Fig. 6. Calcium is concentrated around the Saint's face and the wooden cross. Intense brownish colours exhibit the highest contents of iron $\left(711 \mu \mathrm{g} / \mathrm{cm}^{2}\right)$ and major presence of manganese $\left(38.2 \mu \mathrm{g} / \mathrm{cm}^{2}\right)$. Lead is widely distributed all over the piece, although the amount of lead is several times higher in the carnations $\left(7539 \mu \mathrm{g} / \mathrm{cm}^{2}\right)$ indicating their additional use for the base pigment at these parts. Reddish parts of the picture (lips, eyebrows and carnations) exhibit the presence of mercury being the highest one in the Saint's lips $\left(572 \mu \mathrm{g} / \mathrm{cm}^{2}\right)$. Gold is restricted to golden crown $\left(585 \mu \mathrm{g} / \mathrm{cm}^{2}\right)$.

For the proper interpretation of the whole dataset, a PCA routine was carried out. Gold (Au) was not taken into account since it is only characteristic of the golden crown. By comparing the compositional pattern (the selected variables were $\mathrm{Ca}, \mathrm{Mn}, \mathrm{Fe}, \mathrm{Hg}$ and $\mathrm{Pb}$ ) the principal component analyses allowed us to differentiate colours according to their elemental content. The extraction of two factors implies the $68 \%$ of the explained variance. Factor 1, explaining the $47 \%$ of the total variance, has positive high loads for Mn and iron while Factor 2, which explains the $21 \%$ of the total variance, has a strong negative load for Hg. As shown in Fig. 7, which illustrates the position of different cases respect to the two main 
factors, 3 main groups can be observed. The first group (Fig. 7a) is composed by red tonalities (lips and skin-coloured carnations); brownish shades (light and dark brown from clothes and orangey brown from the cross) compound the second group (Fig. 7b) while the third one is composed by green and golden colours (Fig. 7c).

\subsubsection{Pigment mass distribution estimation on a Contemporary painting}

As revealed by the spectral data obtained by EDXRF analyses we can observe the presence of $\mathrm{Ca}, \mathrm{Mn}$, $\mathrm{Cr}, \mathrm{Fe}, \mathrm{Cu}, \mathrm{Zn}, \mathrm{Cd}$ and $\mathrm{Pb}$.

Zinc signal is present in all the spectra and it can appear as a result of the emission of zinc-bearing brass from support and also by its potential presence in the pigments. As it has happened with copper in the Renaissance portrait, we cannot clearly differentiate by EDXRF analysis whether the potential contribution of the zinc signal in the spectra is related to the pictorial layer, the supporting base or from both of them; however, by using XRD analysis the presence of zincite $(\mathrm{ZnO})$ was recorded (Fig. 8). The presence of this compound revealed the use of modern pigments such as zinc white, which is not typical in paintings before the middle of the nineteenth century.

The main results relating to the elemental chemistry of the Contemporary painting are summarized in Table 3. The relationship between colouration and chemical data can be deduced from the elemental surface distribution illustrated in Fig. 9. Calcium and lead are distributed all over the piece. Highest contents are found on the white shades but also in other colours, what suggest that they were probably used as a pigmenting supports. (Ca: $2258 \mu \mathrm{g} / \mathrm{cm}^{2}, \mathrm{~Pb}: 14416 \mu \mathrm{g} / \mathrm{cm}^{2}$ ). Cadmium is restricted to pinkish and orangey colours $\left(704 \mu \mathrm{g} / \mathrm{cm}^{2}\right.$ and $305 \mu \mathrm{g} / \mathrm{cm}^{2}$ respectively). The highest contents of iron are recorded in the green flag, although the brownish parts of the picture also show iron in relevant amount (445 $\mu \mathrm{g} / \mathrm{cm}^{2}$ and $189 \mu \mathrm{g} / \mathrm{cm}^{2}$ respectively). The presence of manganese is restricted to warm colours (pink, orange and brown) and its content is often at trace level. Chromium is mainly distributed in both the bluish and yellowish shades of the sky and the water (being the highest contents $1567 \mu \mathrm{g} / \mathrm{cm}^{2}$ for the sky and $180 \mu \mathrm{g} / \mathrm{cm}^{2}$ for water). 
Statistical routine was also performed to the obtained semi-quantitative data from this artwork. The first two factors found for the River landscape "oil on copper" painting explain the $71 \%$ of the variability of the system. Factor 1, which explains the $38.86 \%$ of the total variance, has high positive load for Ca and negative load is for Fe. Factor 2, explaining the $32.26 \%$ of the total variance, has high positive loads for $\mathrm{Pb}$ while a high negative load of this factor for $\mathrm{Cr}$. In Fig. 10, which represents the position of the different cases respect to the two main factors, we broadly distinguish 3 main clusters: clusters corresponding to warm tonalities and the green colour are found approximately in the same region of the scatter plot and constitute the first cluster (Fig. 10a); the second one is constituted by bluish and yellow tonalities from both the sky and the water (Fig. 10b) and the third cluster is composed by white colour (Fig. 10c).

\section{Conclusions}

Two "oil on copper" paintings, from presumable different ages, were investigated and characterized by X-ray spectroscopy (X-ray diffraction and energy dispersive X-ray fluorescence) revealing differences not only in the support and in the preparation layers but also in the elemental chemistry of pigments.

In both cases, results of the analyses suggest that there are at least 2 superimposed layers (apart of the supporting media made of copper or brass): a priming coat mainly composed by lead white and a pictorial layer of different composition (depending on the area of analysis).

The first painting, attributed to the Renaissance period, is characterized by a copper plate support, a white lead pictorial base $\left(\mathrm{Pb}\left(\mathrm{CO}_{3}\right)_{2} \cdot \mathrm{Pb}(\mathrm{OH})_{2}\right)$ and the presence of $\mathrm{Ca}, \mathrm{Mn}, \mathrm{Fe}, \mathrm{Cu}, \mathrm{Au}, \mathrm{Hg}$ and $\mathrm{Pb}$. The second one, presumably from the second half of the eighteenth century and made over a brass support, is characterized by a white lead pictorial base $\left(\mathrm{Pb}\left(\mathrm{CO}_{3}\right)_{2} \cdot \mathrm{Pb}(\mathrm{OH})_{2}\right.$ and $\left.\mathrm{PbCO}_{3}\right)$ and the presence of $\mathrm{Ca}, \mathrm{Cr}$, $\mathrm{Mn}, \mathrm{Fe}, \mathrm{Cu}, \mathrm{Zn}, \mathrm{Cd}$ and $\mathrm{Pb}$. The presence of white lead as a preparation layer suggest that both artworks where conceived before the nineteenth century since it was on that period when the use of white lead was progressively abandoned due to its high toxicity [2].

The compositional features, revealed by the combined use of XRD and EDXRF, not only suggest that the second painting is more recent than the attributed to Renaissance period but also confirm that the second 
one (the River Landscape "oil on copper" painting) was in fact carried out at the end of the eighteenth century (the joint presence of chromium and cadmium was recorded and the presence of zinc white, a pigment that was commercially available at the end of the eighteenth century [22], were observed). This chronology is in accordance with the stylistic features described by the art historians.

A simple and rapid method based on non-invasive direct analysis of solid sample was developed for the determination of pigment mass distribution of "oil on copper" multilayered paintings by using the WinFTM® Software Program version 6.20 (Helmut Fischer GmbH, Germany). The method is calibrated by using the dried residues of small droplets of pure elemental solutions, thus obtaining the sensitivity library for estimations of the areal absolute mass distribution. The program allows the possibility to compensate spectral differences from different metallic supports used to create these paintings, by introducing the whole spectrum of standard's support, and the spectrum of the pictorial support. By treating the obtained results with the proper statistical routines (such as Principal Component Analyses) it is possible to find out some differences between colours according to their elemental content.

\section{Acknowledgements}

The authors would like to express their gratitude to Josep Elvira from the Service of X-Ray Diffraction of the ICTJA-CSIC for his valuable help on the experimental tasks and to Marta Rejas and Mercè Cabañas for supplying us the standard solutions. A. Pitarch gratefully acknowledges the Spanish Ministry of Education for the grant within the program of Formation of Graduate Stuff - FPU (reference AP20064591). This study has been done within the framework of the PhD program in Geology of the Autonomous University of Barcelona (UAB).

\section{References}

[1] Komanecky M K, Horovitz I, Eastaugh N (1998) Painting Techniques History, Materials and studio Practice. Contributions to the Dublin Congress, 7-11 September 1998, Dublin. pp. 136-139

[2] Carlyle L (2001) The Artist's assistant: oil painting instruction manuals and handbooks in Britain 1800-1900: with reference to selected eighteenth-century sources. Archetype Publications, London

[3] Queralt I, Ibañez J, Marguí E, Pujol J (2010) Spectrochim Acta Part B (2010) 65 (7): 583 -586

[4] Scott D A, Warmlander S, Mazurek J, Quirke S (2009) J Archeol Sci 36: 923 -932 
[5] Desnica V, Skaric K, Jembrih-Simbuerger D, Fazinic S, Jaksic M, Mudronja D, Pavlicic M, Peranic I, Schreiner M (2008) Appl Phys A 92: 19 -23

[6] Gil M, Carvalho M L, Seruya A, Ribeiro I, Queralt I, Candeias A E, Mirao J (2008) Appl Phys A 90: $49-54$

[7] Sotiropoulou S, Sister Daniilia, Millan C, Rosi F, Cartechini L, Papanikola-Bakirtzis D (2008) Appl Phys A 92: $143-150$

[8] Desnica V, Schreiner M (2006) X-Ray Spectrom 35: 280 -286

[9] Bonizzoni L, Colombo C, Ferrati S, Gargano M, Greco M, Ludwig N, Realini M (2011) A critical analysis of the application of EDXRF spectrometry on complex stratigraphies. X-Ray Spectrom. Doi: $10.1002 / x r s .1320$

[10] Bertucci M, Bonizzoni L, Ludwig N, Milazzo M (2010) X-Ray Spectrom 39: 135 -141

[11] Bonizzoni L, Caglio S, Galli A, Poldi G (2010) X-Ray Spectrom 39: 233 -242

[12] Bonizzoni L, Caglio S, Galli A, Poldi G (2008) Appl Phys A 92: 203 -210

[13] Cesareo L, Bruneti A, Ridolfi S (2008) X-Ray Spectrom 37: 309 -316

[14] Bonizzoni L, Galli A, Poldi G, Milazzo M (2007) X-Ray Spectrom 36: 55-61

[15] Stulik D C, Khanjian H P (2003) In: Townsend JH, Eremin K, Adriaens A (eds.) Conservation Science 2002, Archetype Publications, London

[16] Pappalardo L, Pappalardo G, Amorini F, Branciforti M G, Romano F P, Sanoit J, Rizzo F, Scafiri E, Taormina A, Rotondo G (2008) X-Ray Spectrom 37: 370 -375

[17] Dupuis G, Menu M (2006) Appl Phys A 83: 469 -474

[18] Fittschen UEA, Havrilla GJ (2010) Anal Chem 82: 297-306

[19] Roessiger V, Nensel B (2006) In: Beckhoff B, Kannigieber B, Langhoff N, Wedell R (eds.) Handbook of Practical X-ray Fluorescence Analysis, Springer-Verlag, Berlin

[20] Roessiger V, Kaiser K H (1998) WinFTM: eine neue Software für die Schichtdickenmessung nach dem Röntgenfluoreszenz-Verfahren, Jahrbuch Oberflächentechnik, Metall Verlag, Heidelberg, p. S313 [21] Gilbert B, Denoël S, Weber G, Allart D (2003) Analyst 128:1213-1217

[22] Eastaugh N, Walsh V, Chaplin T, Siddal R (2004) Pigment Compendium, a dictionary of historical pigments. Elsevier Butterworth - Henemann, Oxford. 
Table 1 Estimated areal detection limits $\left(\mu \mathrm{g} \cdot \mathrm{cm}^{-2}\right)$

\begin{tabular}{ccccccccc}
\hline $\mathrm{Ca}$ & $\mathrm{Cr}$ & $\mathrm{Mn}$ & $\mathrm{Fe}$ & $\mathrm{Zn}$ & $\mathrm{Cd}$ & $\mathrm{Au}$ & $\mathrm{Hg}$ & $\mathrm{Pb}$ \\
\hline 14.4 & 2.6 & 3.1 & 2.7 & 5.9 & 7.7 & 5.3 & 6.9 & 4.2 \\
\hline
\end{tabular}


Table 2 Elemental concentration values $\left(\mu \mathrm{g} \cdot \mathrm{cm}^{-2}\right)$ from different areas of the "oil on copper" portrait

\begin{tabular}{|c|c|c|c|c|c|c|}
\hline & $\mathrm{Ca}$ & $\mathrm{Mn}$ & $\mathrm{Fe}$ & $\mathrm{Au}$ & $\mathrm{Hg}$ & $\mathrm{Pb}$ \\
\hline \multicolumn{7}{|c|}{ skin coloured } \\
\hline $\min$ & $\operatorname{tr}$ & $\operatorname{tr}$ & $\operatorname{tr}$ & nd & 29.9 & 5814 \\
\hline $\max$ & 175 & $\operatorname{tr}$ & 38.8 & - & 157 & 7539 \\
\hline \multicolumn{7}{|l|}{ red } \\
\hline $\min$ & 62.0 & $\operatorname{tr}$ & 59.9 & nd & 229 & 1093 \\
\hline $\max$ & 180 & 6.3 & 110 & - & 572 & 1816 \\
\hline \multicolumn{7}{|c|}{ orangey brown cross } \\
\hline $\min$ & 50.6 & $\operatorname{tr}$ & 358 & nd & 0 & 1835 \\
\hline $\max$ & 173 & 14.2 & 643 & - & 65.2 & 3193 \\
\hline \multicolumn{7}{|c|}{ green } \\
\hline $\min$ & $\operatorname{tr}$ & $\operatorname{tr}$ & 54.9 & nd & nd & 827 \\
\hline $\max$ & 79.1 & 5.3 & 112 & - & - & 1043 \\
\hline \multicolumn{7}{|c|}{ dark brown clothes } \\
\hline $\min$ & 120.4 & 12.5 & 353 & nd & $\operatorname{tr}$ & 829 \\
\hline $\max$ & 163.3 & 38.2 & 711 & - & 33.2 & 1598 \\
\hline \multicolumn{7}{|c|}{ light brown clothes } \\
\hline $\min$ & 104 & 6.2 & 91.5 & nd & $\operatorname{tr}$ & 2001 \\
\hline $\max$ & 182 & 11.1 & 111 & - & 15.4 & 2638 \\
\hline \multicolumn{7}{|c|}{ crown } \\
\hline $\min$ & 28.9 & $\operatorname{tr}$ & 62.4 & 463 & 11.7 & 935 \\
\hline $\max$ & 54.8 & 3.5 & 76.1 & 585 & 30.9 & 1023 \\
\hline
\end{tabular}

nd: non detected

tr: traces 
Table 3 Elemental concentration values $\left(\mu \mathrm{g} \cdot \mathrm{cm}^{-2}\right)$ from different areas of the "oil on copper" river landscape

\begin{tabular}{|c|c|c|c|c|c|c|}
\hline & $\mathrm{Ca}$ & $\mathrm{Cr}$ & $\mathrm{Mn}$ & $\mathrm{Fe}$ & $\mathrm{Cd}$ & $\mathrm{Pb}$ \\
\hline \multicolumn{7}{|c|}{ Orange man } \\
\hline $\min$ & 282 & 15.0 & 6.8 & 215 & 554 & 2290 \\
\hline $\max$ & 792 & 27.9 & 28.7 & 349 & 703 & 3782 \\
\hline \multicolumn{7}{|c|}{ Orange Boatman } \\
\hline $\min$ & 179 & 23.9 & $\operatorname{tr}$ & 55.3 & 340 & 1917 \\
\hline $\max$ & 473 & 32.1 & 9.0 & 95.1 & 475 & 2901 \\
\hline \multicolumn{7}{|c|}{ Pink House } \\
\hline $\min$ & 341.4 & 8.1 & $\operatorname{tr}$ & 45.5 & 248 & 1748 \\
\hline $\max$ & 415.4 & 14.7 & 3.9 & 67.0 & 305 & 2526 \\
\hline \multicolumn{7}{|c|}{ Dark Brown Bridge } \\
\hline $\min$ & 70.9 & 8.5 & $\operatorname{tr}$ & 84.3 & 0.0 & 570 \\
\hline $\max$ & 155 & 12.9 & 9.7 & 188 & 26.8 & 754 \\
\hline \multicolumn{7}{|c|}{ Green flag } \\
\hline $\min$ & 184 & 7.1 & 3.7 & 251 & $\operatorname{tr}$ & 1101 \\
\hline $\max$ & 421 & 18.0 & 10.5 & 445 & 50.8 & 2835 \\
\hline \multicolumn{7}{|c|}{ Blue Water } \\
\hline $\min$ & 341 & 45.0 & nd & $\operatorname{tr}$ & 10.9 & 2015 \\
\hline $\max$ & 900 & 180 & - & 20.5 & 73.5 & 4461 \\
\hline \multicolumn{7}{|c|}{ Blue Sky } \\
\hline $\min$ & 545 & 52.0 & $\operatorname{tr}$ & $\operatorname{tr}$ & 20.3 & 3220 \\
\hline $\max$ & 872 & 87.8 & 3.7 & 21.7 & 74.1 & 4456 \\
\hline \multicolumn{7}{|c|}{ Yellow Sky } \\
\hline $\min$ & 192 & 118 & $\operatorname{tr}$ & 3.2 & $\operatorname{tr}$ & 1523 \\
\hline $\max$ & 372 & 157 & 9.6 & 20.7 & 21.3 & 1941 \\
\hline \multicolumn{7}{|c|}{ White Sky } \\
\hline $\min$ & 1055 & $\operatorname{tr}$ & $\operatorname{tr}$ & $\operatorname{tr}$ & 41.6 & 6909 \\
\hline $\max$ & 2258 & 16.8 & 14.2 & 33.2 & 77.5 & 14416 \\
\hline
\end{tabular}


nd: non detected

tr: traces

6 
Figure captions

Fig. 1. Portrait of Saint Bernardino of Siena “oil on copper” painting.

Fig. 2. River landscape "oil on copper" painting.

Fig. 3. Plot of RSD vs. measuring time for Mn. Experimental conditions: 6 measurements on each point, Al $1000 \mu \mathrm{m}$ filter, $50 \mathrm{kV}, 1000 \mu \mathrm{A}$, focal spot $1 \mathrm{~mm}$.

Fig. 4. a) EDXRF spectrum from the backside of the Renaissance painting and b) EDXRF spectrum from the backside of the Contemporary artwork.

Fig. 5. a) Diffractogram of the Renaissance painting and b) diffractogram of the Contemporary artwork Key: \#: copper alloy; *: hydrocerussite; +: copper sulphate compound; v: calcite; $\beta$ : brass (Cu-Zn alloy); \&: cerussite; ^: gypsum; $\gamma:$ zincite.

Fig. 6. a) Detailed image of the studied area showing the gridding of the X-ray map. Elemental surface distribution in $\mu \mathrm{g} \mathrm{cm}^{-2}$ of: b) $\mathrm{Ca}$; c) $\mathrm{Fe}$; d) $\mathrm{Pb}$; e) $\mathrm{Hg}$ and f) $\mathrm{Au}$.

Fig. 7. Scatter plot of Factor 1 vs. Factor 2 of the analysed areas from the Renaissance painting. Red colour is represented by black circles; skin colour is shown by black squares; dark brown is represented by black triangles; orangey-brown is shown by black rhombus; light brown is represented by triangles; golden is represented by stars and green colour is shown by circles.

Fig. 8. Diffractograms of the Contemporary artwork obtained in different areas: i) blue water; ii) blue sky. Key: *: hydrocerussite; v: calcite; $\beta$ : brass $(\mathrm{Cu}-\mathrm{Zn}$ alloy); $\gamma$ : zincite.

Fig. 9. a) Detailed image of the studied area from the Contemporary painting illustrating the gridding of the X-ray map. Elemental surface distribution in $\mu \mathrm{g} \mathrm{cm}^{-2}$ of: b) $\mathrm{Ca}$; c) $\mathrm{Cr}$; d) $\mathrm{Fe}$; e) $\mathrm{Cd}$ and f) $\mathrm{Pb}$.

Fig. 10. Scatter plot of Factor 1 vs. Factor 2 of the analysed areas from the Contemporary painting. Orange colour from the man is represented by black circles; orange colour from the boatman is shown by circles; brown colour is shown by black squares; yellow is represented by black triangles; blue from the sky is shown by black rhombus; the blue from the water is represented by rhombus; green is shown by triangles; white is represented by stars and pink colour is shown by squares. 


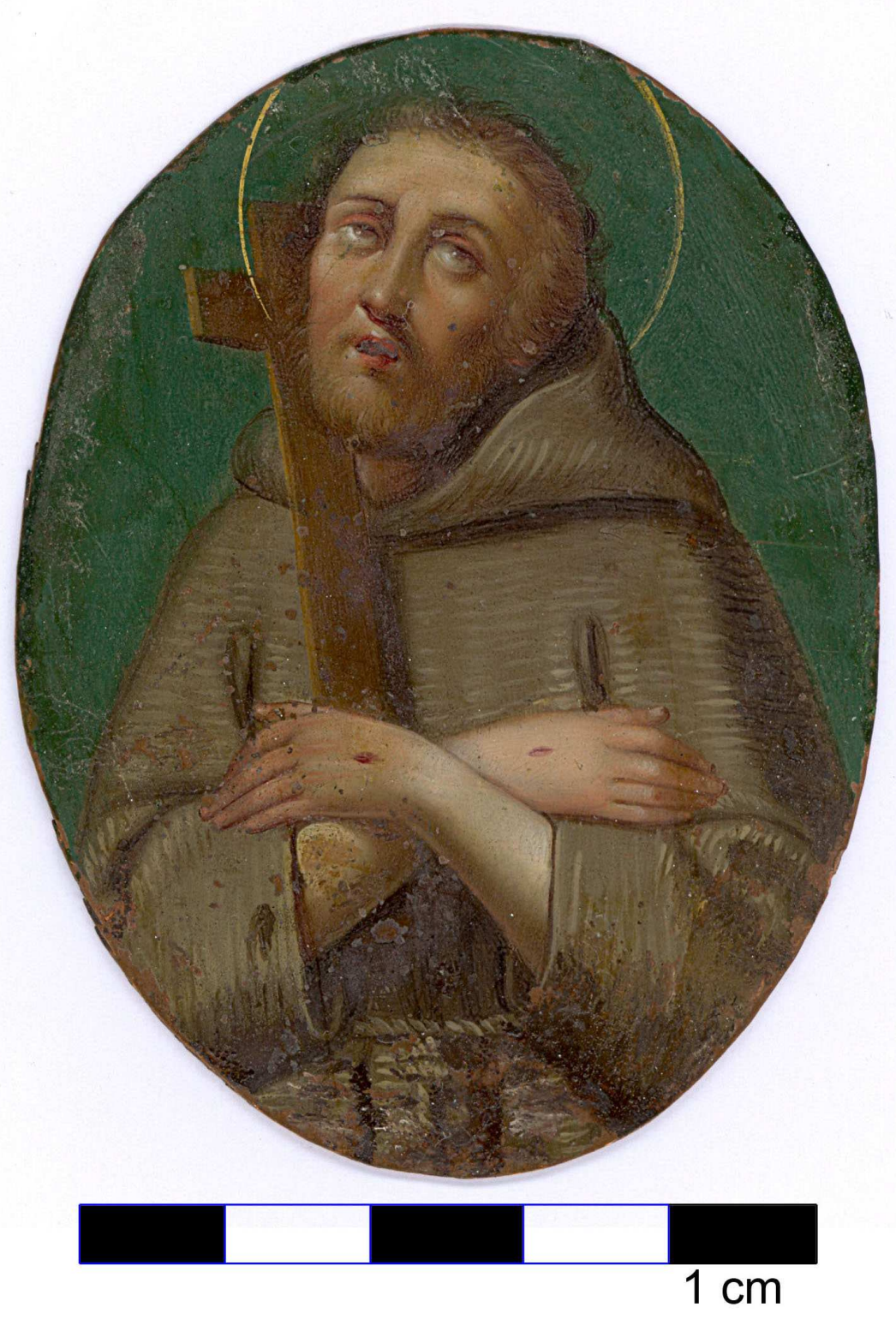

Figure 1

$61 \times 90 \mathrm{~mm}(600 \times 600 \mathrm{DPI})$ 


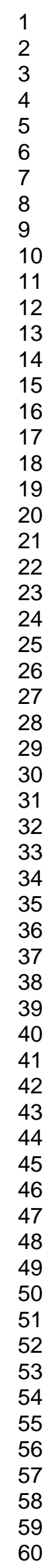

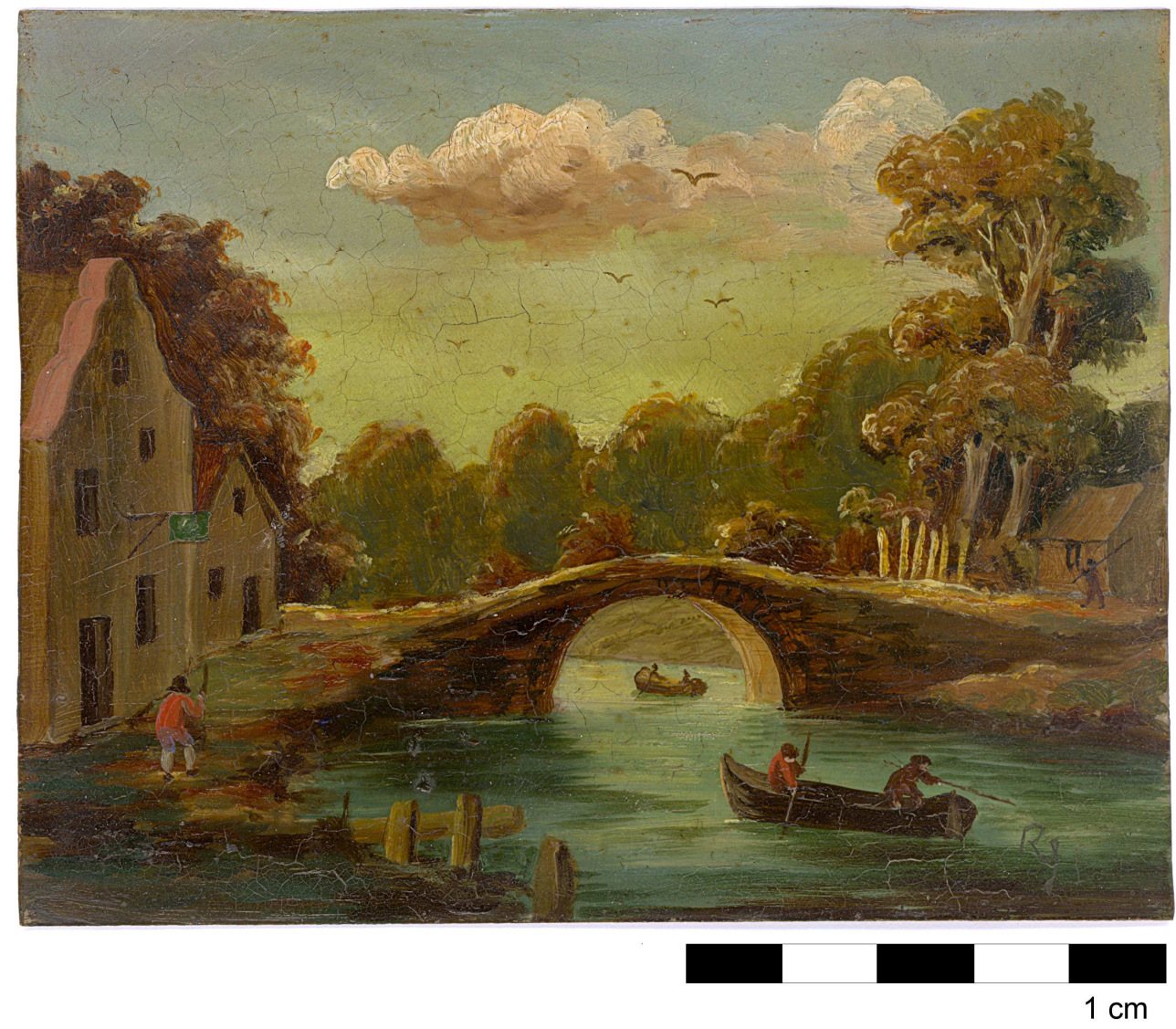

Figure 2

$124 \times 108 \mathrm{~mm}(600 \times 600 \mathrm{DPI})$ 


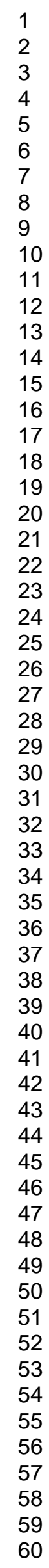

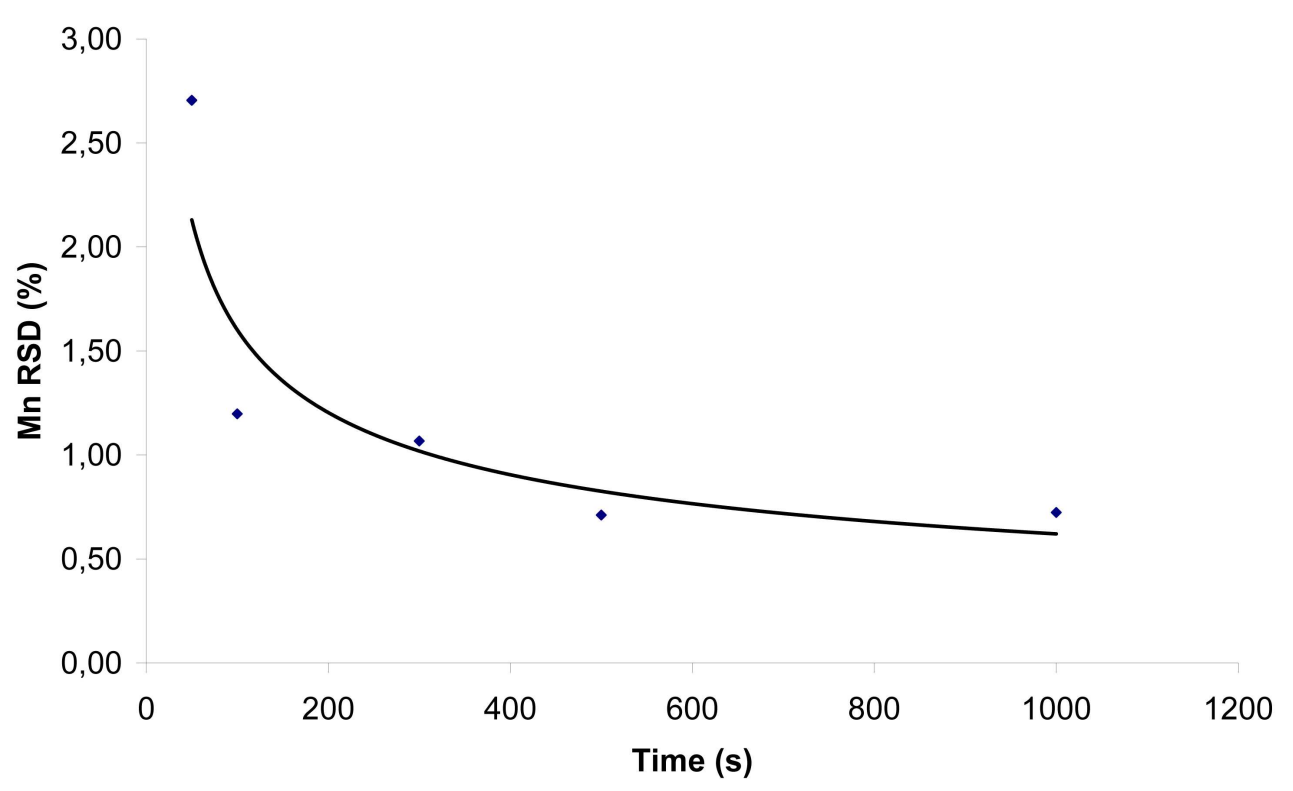

Figure 3 $253 \times 156 \mathrm{~mm}$ ( $300 \times 300$ DPI) 
a)

b)
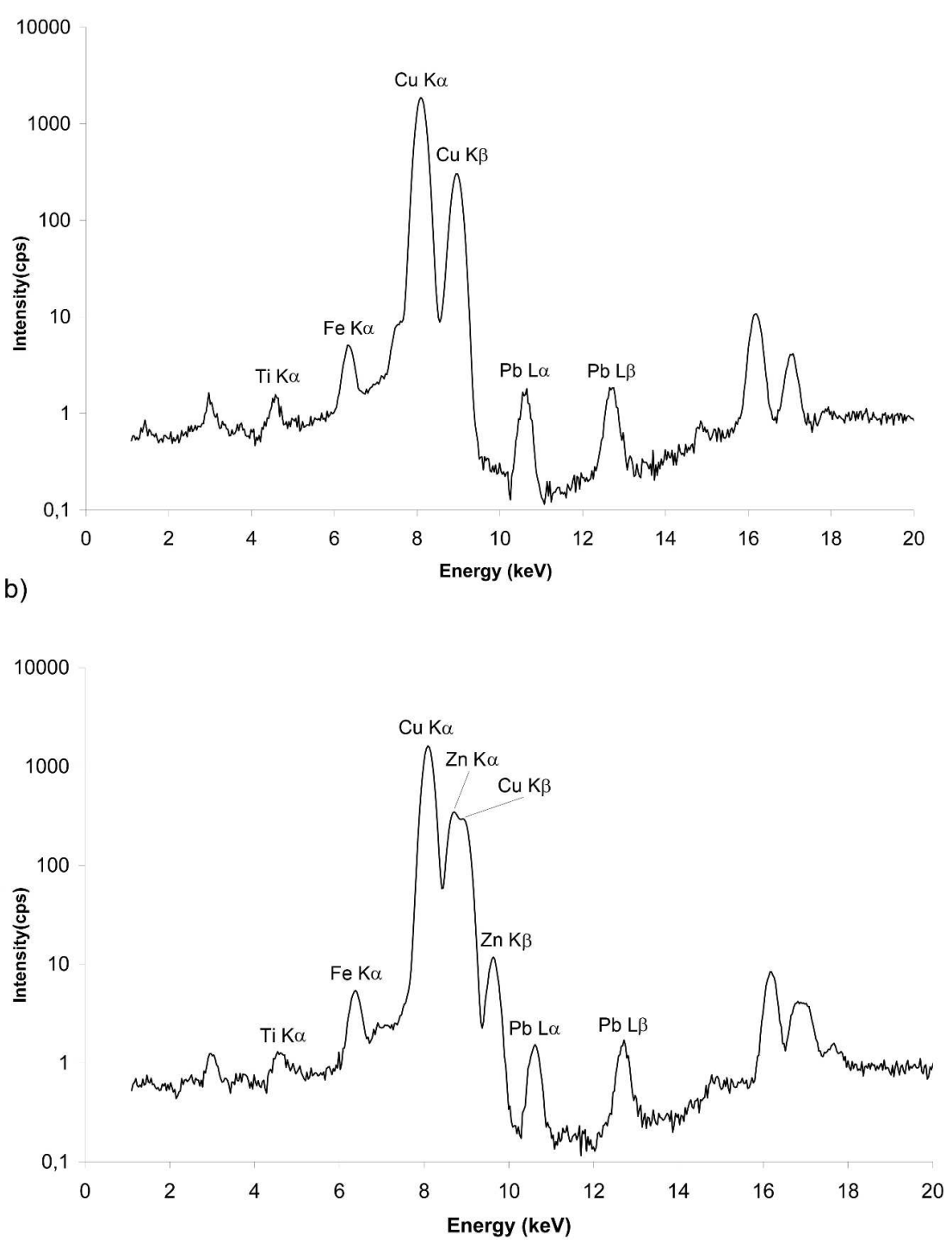

Figure 4 $235 \times 320 \mathrm{~mm}(300 \times 300$ DPI $)$ 

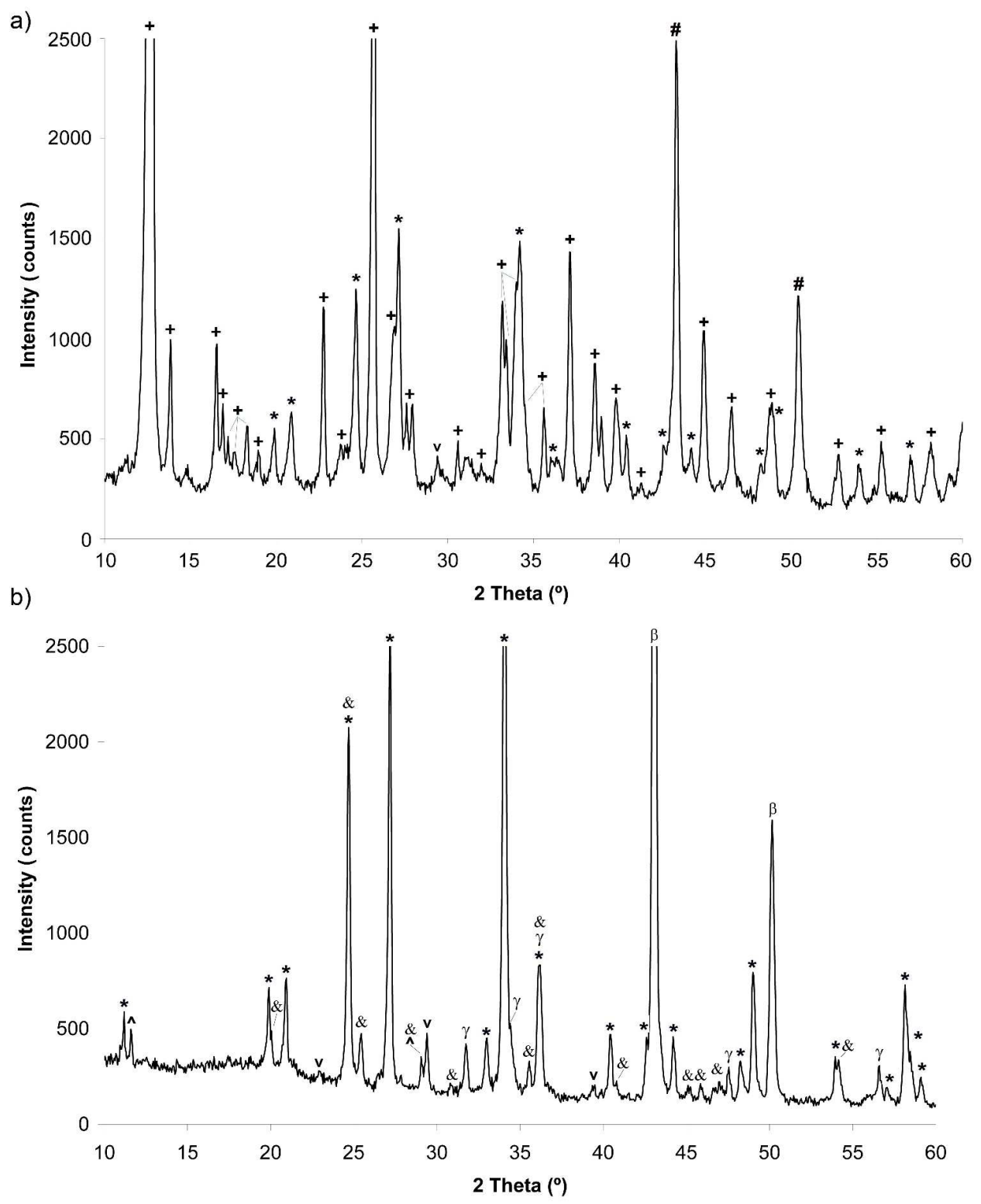

Figure 5 $259 \times 320 \mathrm{~mm}(300 \times 300 \mathrm{DPI})$ 
a)

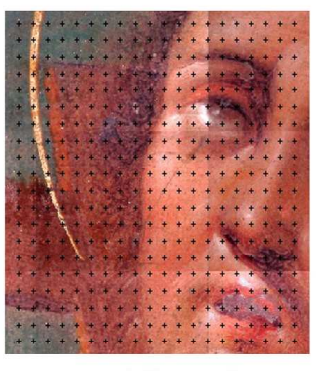

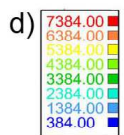

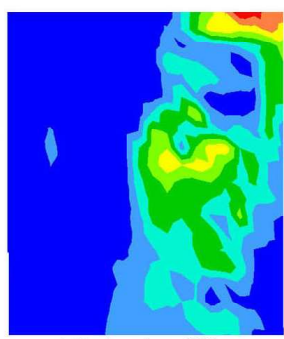

$\mathrm{Pb}\left(\mathrm{ug} / \mathrm{cm}^{\wedge} 2\right)$ b)

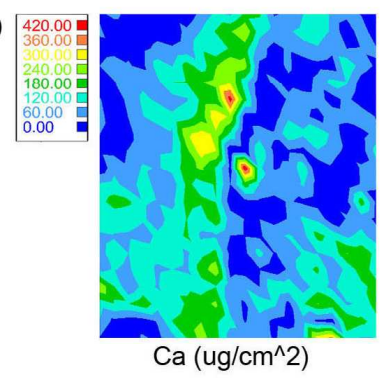

e)

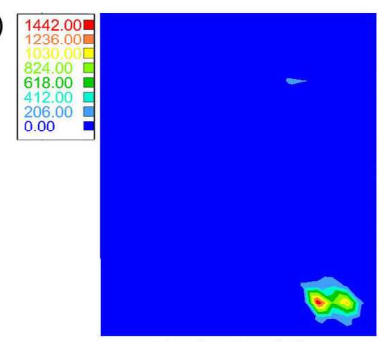

$\mathrm{Hg}\left(\mathrm{ug} / \mathrm{cm}^{\wedge} 2\right)$

Figure 6

$157 \times 95 \mathrm{~mm}(600 \times 600 \mathrm{DPI})$ c)
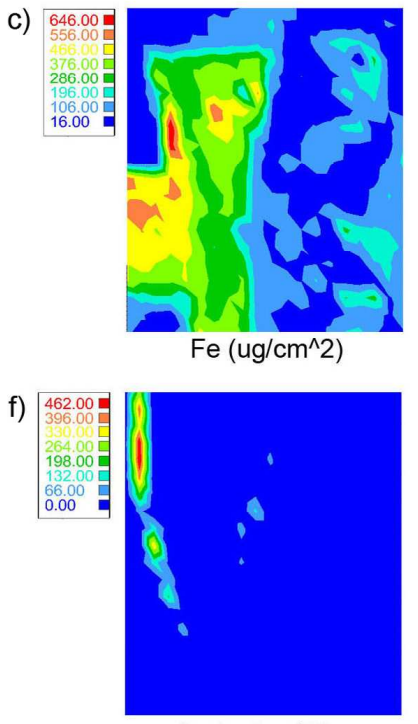

$\mathrm{Au}\left(\mathrm{ug} / \mathrm{cm}^{\wedge} 2\right)$ 


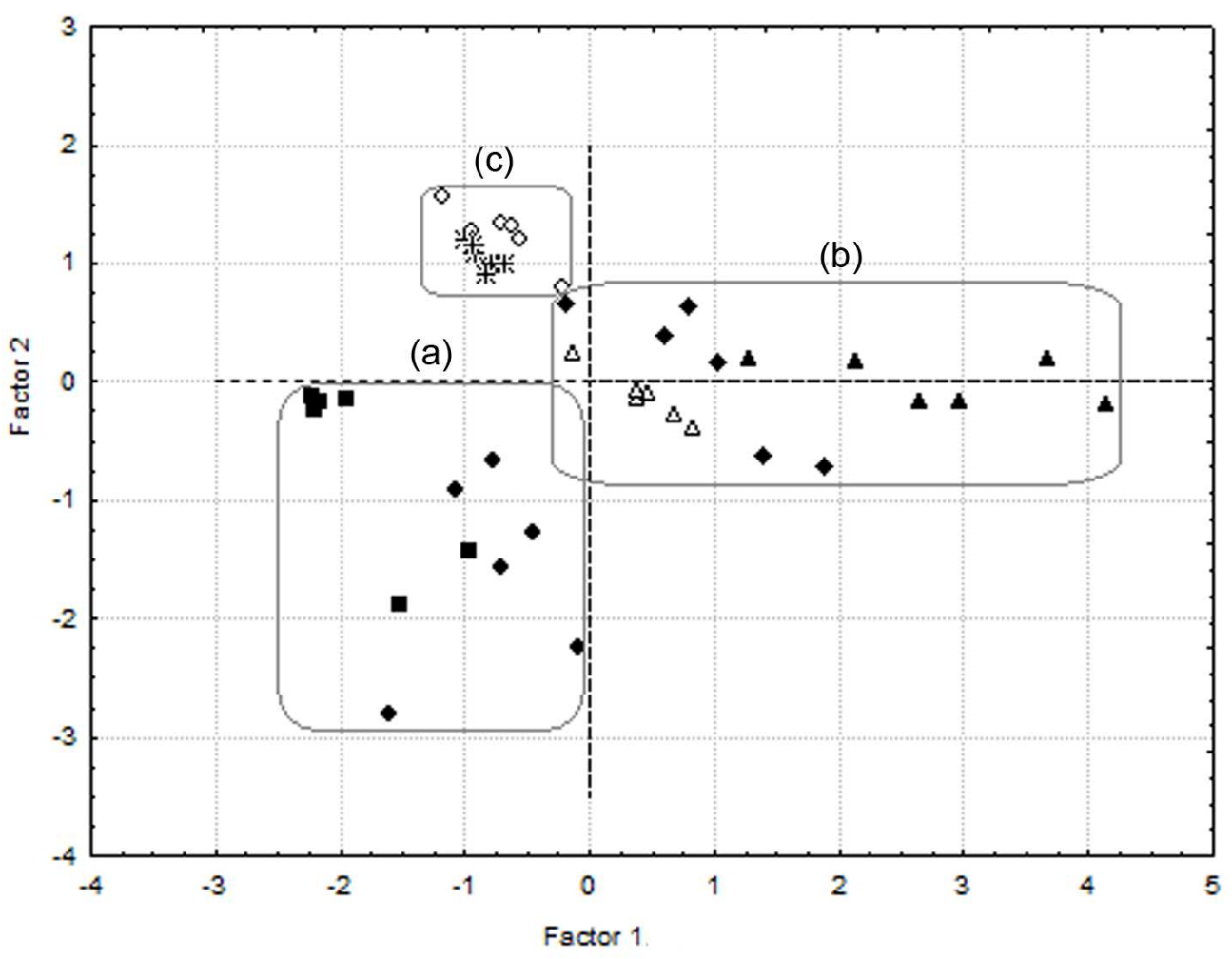

Figure 7

$123 \times 95 \mathrm{~mm}(300 \times 300 \mathrm{DPI})$ 
Page 25 of 27

Analytical \& Bioanalytical Chemistry

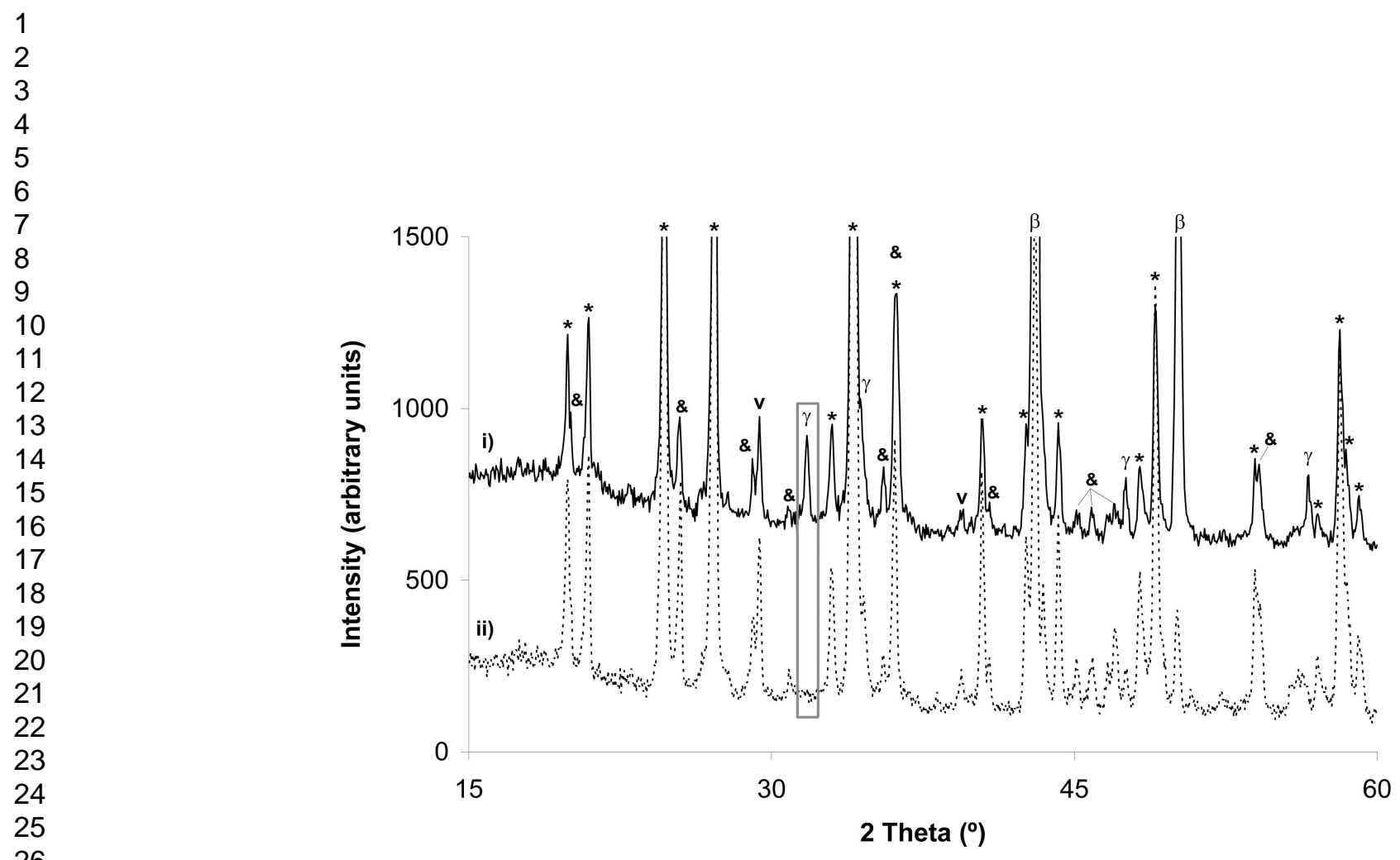

Figure 8

$253 \times 156 \mathrm{~mm}(300 \times 300$ DPI $)$ 
a)

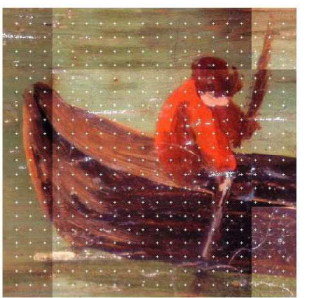

d)

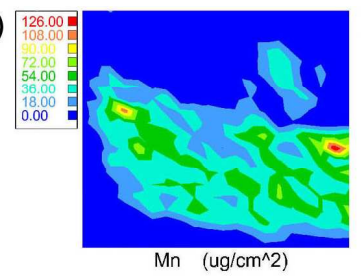

g)

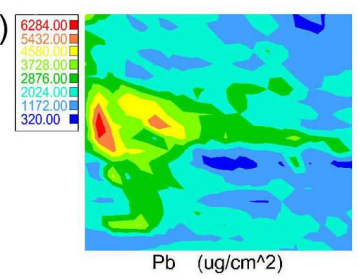

b)

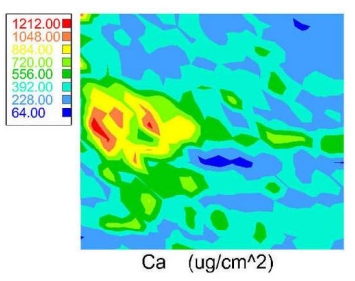

e)

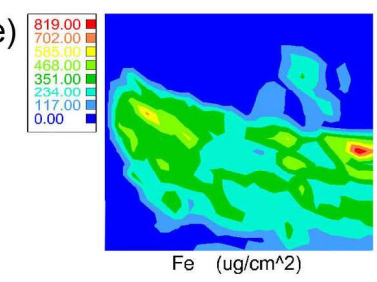

c)
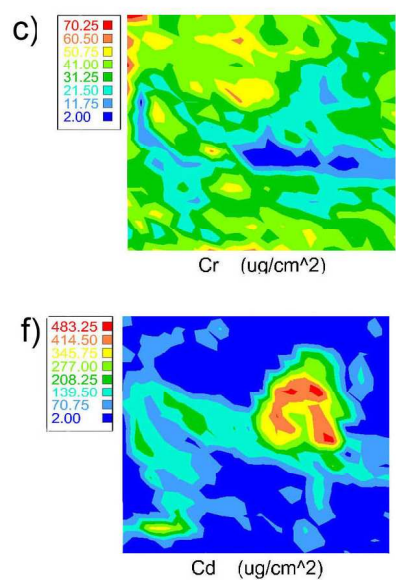

Figure 9

$170 \times 116 \mathrm{~mm}(600 \times 600 \mathrm{DPI})$ 


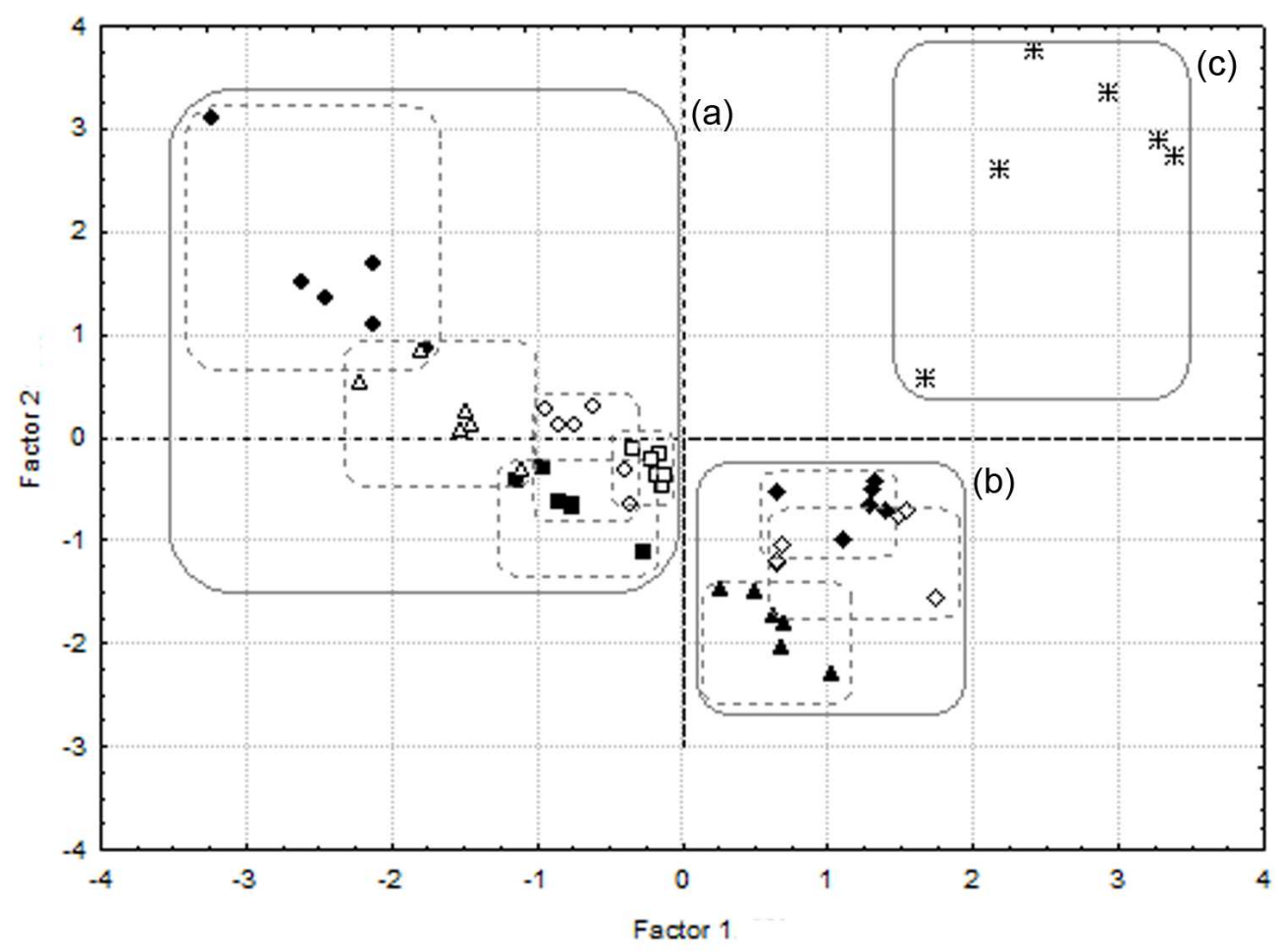

Figure 10

$127 \times 95 \mathrm{~mm}(300 \times 300$ DPI)

1

2

3

4

5

6
7

8

9

10

11

13

14

15

16

17

19

20

21

22

24

25

26

27

28
29

30

31

32

33

34

35

36

37

38

39

40

41

42

43

44

45

46

47

48

49

50

51

52

53

54

55

56

57

58

59

60 